\title{
A Survey on the Influence of Applying Office Automation System on Employees' Knowledge and Attitude About Influenza in Tehran University of Medical Sciences
}

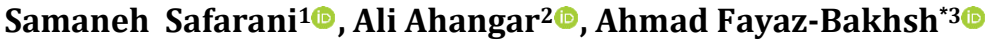

1- Ph.D. Student in Health Care Management, School of Management and Medical Information, Iran University of Medical Sciences, Tehran, Iran. 2- Ph.D. student in Health Economics, School of Management \& Economics, Tarbiat Modarres University, Tehran, Iran.

3- Health Information Management Research Center, School of Allied Medical Sciences, and Department of Health Education, School of Public Health, Tehran University of Medical Sciences, Tehran, Iran.

\section{ABSTRACT}

Introduction: Influenza is a highly contagious disease and is common in cold seasons. High prevalence of influenza in workplace causes severe economic damages. Thus any employer would be interested in preventing this using appropriate tools. Influenza illness in primary prevention can be achieved by teleeducating target group, and change their knowledge as well as attitude and behavior in this goal by sending message on automation system or e-mail. In this study, the researcher is following the above listed equipment to increase awareness of target group about influenza disease.

Material and Methods: This research is a quasi-experimental study and was done in 2009-2010. The target group (40 employees) were selected from headquarter units in Tehran University of Medical Sciences using stratified - random sampling method. We used two approximately similar questionnaires as Pre-test and Posttest to gather data. For analyzing the data, We used Independent Sample T- Test, One Way ANOVA and Paired Sample T-Test and linear Regression methods.

Results: The Mean age of the study group was 34.82 years old. $30 \%$ of them were men and $70 \%$ were women overall. The mean of answers changed from 35.33 to 42.52 after the intervention indicates significant differences in these results, so the intervention was effective. Age, academic educational level and the field of study did not have any significant relation with changes in knowledge and attitude of the study group, but gender significantly was related to the results.

Conclusion: It could be concluded that with this species plans and the correct use of information and communication technology, particularly in the health field, it can expect not only reduction in different diseases in the future; but also if follow this trend in long time, it will see increase in knowledge of employees, changes in their attitude and finally by its repeating and continuing it may predict reducing in many organizational costs, medical treatment costs and many other expenses. At last, it can suggest using these programs for many other problems in health matters, and many other subjects which influence the costs and benefits of a system.

\section{(i) Please cite this article as:}

Safarani S, Ahangar A, Fayaz-Bakhsh A. A survey on the influence of applying office automation system on employees' knowledge and attitude about Influenza in Tehran University of Medical Sciences. Iran J Med Inform. 2016; 5(1): 6-10. DOI: 10.24200/ijmi.v5i0.108
Article History

Received: 2016-04-05

Accepted: 2016-07-07

Published: 2016-07-15

Keywords

Knowledge

Attitude

Telemedicine

Influenza

\footnotetext{
* Corresponding Author: A Fayaz-Bakhsh, Health Information Management Research Center, School of Allied Medical Sciences, and Department of Health Education, School of Public Health, Tehran University of Medical Sciences, Tehran, Iran (Email: fayaz@tums.ac.ir)
} 


\section{INTRODUCTION}

Influenza virus affects 10 to 20 percent of the world's people population annually. The prevalence of influenza viruses in 1918 killed 50 million people [1]. The number of seasonal influenzaassociated (i.e., seasonal flu-related) deaths varies from year to year because flu seasons are unpredictable and often fluctuate in length and severity. Therefore, a single estimate cannot be used to summarize influenza-associated deaths. Instead, a range of estimated deaths is a better way to represent the variability and unpredictability of flu. An August 27, 2010 MMWR report entitled "Thompson MG et al. Updated Estimates of Mortality Associated with Seasonal Influenza through the 2006-2007 Influenza Season. MMWR 2010; 59(33): 1057-1062" [2]. Provides updated estimates of the range of flu-associated deaths that occurred in the United States during the three decades prior to 2007. CDC estimates that from the 1976-1977 season to the 2006-2007 flu season, flu-associated deaths ranged from a low of about 3,000 to a high of about 49,000 people [2] .

We cannot prevent influenza because its virus antigens change constantly. We should produce a new vaccine against disease virus changes. Furthermore, because of its fast spread to others, if people do not follow a simple principle against it, it will be epidemic and affect all people; this epidemical disease may increase absence from work, costs of curing and decrease in work efficiency and all of these happening causes irreparable damages into a community, so we necessarily need a plan to prevent this infection [2] . Attention to preventive health services is increasing as evidence for their efficacy accumulates $[\underline{2}, \underline{3}]$. Fifty-five million adults aged 18 to 64 years are infected with influenza every year, with 200 million days of restricted activity, 70 million days of work absenteeism, and 18 million visits to health care providers [4].

There was one [1] school closure due to influenza-like illness reported for the surveillance week. Absenteeism due to illness was $3.08 \%$ with $72.47 \%$ of NE schools reporting. 20 schools reported substantial absenteeism related to influenza compared to 23 the prior week. For more information on preventing outbreaks in schools, visit: Guidance for School Administrators to Help Reduce the Spread of Seasonal Influenza in K-12 Schools []․ And all of these can be resulted from low level knowledge and attitude of people on influenza, and this attitude cause's wrong behavior as this people do not know how to behave with their disease and how to promote their health. Moreover, they are not willing to follow health programs such as health periodic studies; therefore. This causes visiting doctors at the latest time when other treatments are not effective enough. All of these, plus inappropriate performance of employees create heavy costs for on the government and society [ 6 ].

According to World Health Organization programs, the first step in pandemic diseases is increasing people's awareness [7].This way can be the best strategy for preventing influenza even when vaccine is not accessible because of its antigen's changing [4]. So when people's knowledge and health increase, those with less income get more ability to attend economic opportunities []. On the other hand, Information technology Means the using of systems, communication networks and computers for processing and data management for the acquisition, storage, and sharing them [9]. Nowadays, information is considered as one of the most important sources of power in the world. The design and implementation of systems and the application of information technologies in general, and "management information systems", in particular, are a respond to this need of information age [10]. Today, in order to planning, decision making and optimal control, management information systems (MIS) is becoming more important day after day. The main purpose of the information and communication technology management in the health sector is accelerating in collecting and accessing and supporting handling health system processes and effective decision making in the management of this system. Because provision and delivering health care and other clinical services for society is a very complex and highly dependent on information systems. Another important point is that health care are eventually services based on information and perhaps knowledge-based services [11].

Office automation system is a communication link between information technology with organizational communications and the use of electronic devices in the office activities is in order to increase the effectiveness and efficiency in the organization [12]. Office automation refers to the use of electronic devices in office activities in order to increase efficiency [13]. Office Automation including all formal and informal electronic systems that relates to data communication between people inside and outside of the institution and vice versa. Office Automation has greatly contributed to increase productivity of the organization in office and administrative work [14]. Office automation is a mechanism which aims to improve organization efficiency and productivity through use of effective and efficient management by utilizing electronic flow of correspondence in organization level, easy searching stored data, quick and timely response to client, removal of paper from administrative correspondence cycle, proper control over users, maintaining and recording data efficiently and improve communications within organization [15].

The most important condition for application and use of automation in most organizations, regardless of its other uses is related to the need of speed and accuracy in their work. It is due to the range development of the organization's operations which this fact need to develop channel information with more speed and office automation causes the communication channels to be short and needed data become readily available for employees and managers. Other advantages of office automation systems can be mentioned as reduced of non-productive activities such as archiving, keeping case history and updating information, better control of work, dependence reduction on other agencies to providing copying, printing and similar matters, less requirement to formality and control for monitoring the work flow between departments, increase of organization customer satisfaction due to providing quick information and timely services and growing phenomenon of distance work (working remotely) [14].

As similar studies of the use of automation to increase awareness confirmed. Computer-based reminder systems have been shown to increase clinicians' rates of compliance with guidelines, especially in preventive health maintenance interventions [1622]. As in this study we used Office Automation System instead of other electronic tools, there were little studies done which evaluated the effects and impacts of using it to facility many works such as illnesses but in a study which evaluated the effects of Office Automation System on employee's productivity in general, its results showed that applying Office Automation System effected on saving employees time, reduce in using papers, increasing the quality of works, and also had impacts on employees productivity in economics in Iran [23].

Telemedicine means using information and communication technology tools in order to primary, secondary and third prevention of diseases. For primary prevention of influenza, we can use telemedicine for educating the target group on different aspects of influenza; for example, its way of transmission and other things by applying office automation system which is the same as electronic mail (E-Mail). In this method, there is no need 
for face to face meetings between the target group and interventionists and our goal which is promoting health level will be achieved.

There is insufficient evidence of efficacy to recommend that client reminders be used alone to increase influenza awareness among persons and employees with high-risk conditions in organization [24]. Interventions to increase client demand in combination with provider-based interventions or interventions to increase access to prevention services (such as vaccination) have been reported to increase vaccination among such persons [244]. However, studies are needed to resolve several issues, including the relationship between frequency of reminders and effectiveness, and identification of the least and most effective combinations of services in multi component interventions [25]. Norouzian and et al in 2011, conducted a research study with title of office automation systems effects on productivity indicators of the organization in the central department of Ferdosi University of Mashhad. Based on the results of this study, more than 50 percent of the society population (central organization staff) believed in the relatively high impact of office automation system on all indicators of productivity and a less than 6 percent of them believe in not effectiveness of system on most parameters of productivity.

In this article, the researcher is following the mentioned above method for intervention (sending messages regularly in time about Influenza to computers of employees) to promote the knowledge of the target group on influenza; obviously, if all conditions for doing it are provided, the target group in Tehran University of Medical Sciences will expose less to influenza and the employer and at least the society reaches more economic efficiency because of decreasing absences which comes from illness, as two important factors of three Human Development Index (concluded education and healthy) have indirectly strong impacts on economic programs by influencing on spreading incomes, and perhaps the effect of education on the health may have more powerful impact. So the objective of this article is increasing the knowledge and positive attitude of the target group around Influenza disease as the results showed below.

\section{MATERIAL AND METHODS}

This study is a quasi-experiment study (because we had no control group and we had just pre-test and post-test) aiming to evaluate the influence of applying office automation system on employees' knowledge and attitude about Influenza in Tehran University of Medical Sciences and was done in 2009-2010. For data gathering, we used 2 questionnaires .The validity of the questionnaires was evaluated by 4 professors in the related fields and a sample questionnaire was used as a guide [4]. The reliability of questionnaires was determined at $90 \%$ by Cronbach's alpha test by SPSS no 16. For sending messages we used Office Automation System that is available at workplaces for all employees instead of E-Mail (electronic mail). Office automation system is a communication link between information technology with organizational communications and the use of electronic devices in the office activities is in order to increase the effectiveness and efficiency in the organization [12]. The study area includes all headquarter staff of Tehran University of Medical Science. The headquarter units in Tehran University of Medical Sciences consists of 9 management departments including educational, supportive , research, Management, finance, technical office and budget departments, Management and Support Services Center and evolution and modernization department. For doing this research, we used stratified - random sampling method, using, we used the table of random numbers and also the department where the employees work there and also identified the target group (40 employees) also after doing this method for a small size sample in 30 people (statistical method to calculate the final sample size) for considering the right sample size by using the Cochran formula of sampling in statistical method, then (pre-test) the questionnaires were distributed and gathered and after that the intervention accurse for one month (each week two messages were sent by office automation system, including 10 messages),at last, the second questionnaire (post-test) was distributed and gathered, and finally the data were entered into SPSS, version No 16 and then were analyzed. For analyzing the data, we used: Independent Sample T- Test, One Way ANOVA and Paired Sample T-Test and linear Regression method modeling.

\section{RESULTS}

The Mean age of study group was 34 years old. $30 \%$ of them were men and $70 \%$ were women. About their level of academic education: $18 \%$ had $\mathrm{PhD} /$ Doctorate, $13 \%$ had MA/MS, and $49 \%$ had BS/BA, 14\% had upper high school diploma, 13\% had high school diploma and $3 \%$ were under high school diploma. About their academic field: $34 \%$ of them graduated in Humanities Sciences, 32\% in Mathematics, 28\% in Medical Sciences, 3\% in Arts and 3\% of them didn't specify their educational field.

According to the data analyzed, Age does not have a significant influence on changes in the knowledge of the study group ( $p$ value $=0.7$ ). Age also doesn't have a significant influence on the changes in the attitude of the study group ( $p$-value $=0.5$ ). Sex was significantly related to changes in the knowledge of the study group ( $\mathrm{p}$-value $=0.02$ ), The mean of changes in knowledge of men was 7.68 but in women, it was 26.35 and this difference means intervention on educating influenza education was more effective in women. However gender though doesn't have a significant influence on changes in the attitude of the study group ( $\mathrm{p}$-value= 0.07).

Table 1: The average of knowledge in target group separated by sex.

\begin{tabular}{|l|l|l|l|}
\hline Sex & N & Mean & Std. Deviation \\
\hline Male & 11 & 24.75 & 22.99 \\
\hline Female & 26 & 12.53 & 17.91 \\
\hline
\end{tabular}

According to the table, the average of knowledge in women was less than men at first, but the average difference was about 4 times more than what it was in men finally.

Academic education level doesn't have a significant influence on changes in the knowledge and attitude of the study group ( $\mathrm{p}$ value $=0.9$ )

Academic field of education also doesn't have a significant influence on changes in the knowledge and attitude of the study group ( $p$-value $=0.75$ ), but changes in the mean of knowledge and attitude showed closer the field of study to influenza (medical field), lower changes in the amount of knowledge and attitude of the study group.

Table 2: The average of knowledge in target group separated by sex.

\begin{tabular}{|l|l|}
\hline Field of education & $\begin{array}{l}\text { The amount of changes in } \\
\text { knowledge and attitude }\end{array}$ \\
\hline Medical Sciences & 12.56 \\
\hline Mathematics & 19.82 \\
\hline Humanities Sciences & 24.69 \\
\hline
\end{tabular}


According to the table, the group with medical sciences had fewer changes in their knowledge and attitude.

To determine the effect of using an automation system on changes in the amount of knowledge around influenza, the mean of knowledge has changed from 15.28 to 36.23 that means the intervention was effective to promote the knowledge of the study group ( $p$-value $=0.02$ ) and the difference in the mean of the knowledge was significant.

To determine the effect of using an automation system on changes in the amount of attitude around Influenza, the mean of attitude has changed from 68.52 to 69.70 that means the intervention was effective to promote the attitude of the study group ( $\mathrm{p}$-value $=0.01)$.

Table 3: The average of knowledge and attitude before and after of intervention in the target group.

\begin{tabular}{|c|c|c|c|}
\hline Factors & Mean(before ) & Mean(after ) & sig \\
\hline Knowledge & 15.28 & 36.23 & 0.02 \\
\hline Attitude & 68.52 & 69.70 & 0.01 \\
\hline
\end{tabular}

According to the table, the mean average changes in knowledge and attitude are significant.

And finally the overall response to the article goal: The information which was sent to employees was mostly about the definition of influenza and its dangers, its way of spreading and transferring, its symptoms and the methods of preventing it. To determine the effects of an automation system on changes in the amount of knowledge and attitude about Influenza shows that the mean of knowledge and attitude of the study group has changed of 35.33 to 42.52 , that means the intervention was effective to promote the knowledge and attitude of the study group ( $\mathrm{p}$-value= 0.041 ) and the difference in the mean of knowledge and attitude was significant.

\section{DISCUSSION}

In this article, we have attempted to provide the most important factors that seem to help the readers be informed about the importance of knowledge on preventing diseases such as Influenza.

Influenza (the flu) is a contagious respiratory illness caused by influenza viruses. It can cause mild to severe illness, and at times can lead to death. Some people, such as older people, young children, and people with certain health conditions, are at high risk of serious flu complications $[\underline{26}, 27]$. There are many ways of preventing Influenza as we saw in the paper published by Center for Disease Control and Prevention that suggests the best way to prevent the flu is getting vaccinated each year [28], although this is a good way, many people do not even know that they should be vaccinated for flu. So here we would again need information.

As mentioned above, we need to use the methods make our people more aware in a very effective way and following this goal we saw, that $\mathrm{Yu}$ from Hong Kong said: While telemedicine can play a vital role during medical crises, on a day-to-day basis the technology also offers many benefits to the medical sector. In Hong Kong, healthcare organizations are under pressure to reduce costs, increase revenues, and deliver the best possible patient care with current available resources; at the same time, they are challenged by the rise in demand for medical care as a result of an aging population, stringent privacy requirements and a shortage of healthcare professionals. With telemedicine, healthcare professionals can offer the elderly remote follow-up appointments given that most of the time these are routine checkups. This will reduce the waiting times at public hospitals and increase productivity. Medical professionals can also easily get access to specialists overseas or even in other local hospitals via tele presence and ask for consultancy and advice when dealing with complicated cases. This reduces the time a patient has to wait for a potential diagnosis and eliminates the need for them to make an appointment with a specialist, ultimately improving the efficiency of the medical system. In short, telemedicine can help medical organizations achieve more with less [29].

In another study this evaluation has implications for public health practice in Switzerland. In the Swiss healthcare setting, a large number of teleconsultations are done on a routine basis. It would therefore be worthwhile to routinely include teleconsultation data in the national influenza surveillance activities. This would be feasible at low additional cost. Specifically, using teleconsultation data may help to identify early beginnings of an influenza outbreak because surveillance reports would be available with almost no lag time. Due to the high number of teleconsultations done in Switzerland, the sensitivity to detect influenza outbreaks earlier may be higher because of the larger population observed and because the barrier to access teleconsultation services may be lower as compared to face-to-

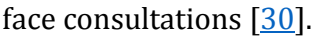

\section{CONCLUSION}

From findings of the research, it can be concluded that this method is useful to aware people about such viruses disease and with applying these plans (Tele-educating people) and the correct use of information and communication technology, particularly in the health field, we can expect not only reduction in different diseases in the future, but also if we follow this method in long time we will see reduction in work absenteeism, the leaving workplaces, cost of organizations, percent of occupied hospital beds, medical treatment, death and in many other expenses, plus the increase in efficiency, income for both employers and employees, money for spending on other needs of life, money for saving and ultimately the day to day improving progress and growing a region, a country and finally prosperity throughout the world as Asefzadeh said that Good Health $(\mathrm{H})$ causes promoting mental - physical manpower abilities (L) and productive manpower increase productions (O) and National income $(\mathrm{Y})$ and increases capital Investment $(\mathrm{I})$, and this in turn increases employment (E), development of social and economic welfare (D) [ㄹ].

Furthermore, our demographic results show that our intervention was more successful in women's group and this finding may have different reasons, for example women pay more attention to details and they are more interested in learning new things and are more precise in every small thing and this is a good method, because women who are mothers at home can teach their children on many subjects, especially about diseases and ways of preventing them, so mothers and women are our one of our main sources that should be paid specific attention for the sake of our goals in various fields such as telemedicine as a famous probe said " if you make a man, you will make one educated person, but if you make a woman educated, you will make a universe educated [].

In addition, based on our demographic finding in the Academic field of study shows that for more effective results we should do more work in groups whose study background is not close to the 
information we want to give them or we want for example to teach the medical groups we should use more specific details to make our study more effective more valuable.

As this method was successful in increasing the knowledge and attitude of people according to the results of the study we can suggest:

- The effect of applying telemedicine on changes in the amount of knowledge, attitude and also behavior of people around influenza or other diseases.

- Reviewing the impact of Information Technology systems on the amount of knowledge and attitudes of different groups of people around various issues.

\section{ACKNOWLEDGMENT}

The author would like to thank project team for cooperation to accomplish this work and also thank all university employees who participated in this study. Lastly, thanks for the almighty, all the participants without whom this assignment would not be possible.

\section{REFERENCES}

1. Fayrz W. Return results about the flu vaccine (Farahani translator). Site Jam. 2009.

2. Thompson MG, Shay DK, Zhou H, Bridges CB, Cheng PY, Burns E, et al. Estimates of deaths associated with seasonal influenza - United States, 1976-2007. Morbidity and Mortality Weekly Report. 2010; 59(33): 1057-62.

3. Asefzadeh S. Principles of health economics. Haditheemruz Publication; 2008.

4. Office of Disease Prevention and Health Promotion. Clinician's handbook of preventive services. 2nd ed. U.S. Department of Health and Human Services. 1998.

5. Tang PC, LaRosa MP, Newcomb C, Gorden SM. Measuring the effects of reminders for outpatient influenza immunizations at the point of clinical opportunity. J Am Med Inform Assoc. 1999; 6(2): 115-21. PMID: 10094064 [PubMed]

6. Bourgeois FT, Simons WW, Olson K, Brownstein JS, Mandl KD. Evaluation of influenza prevention in the workplace using personally controlled health record: Randomized controlled trial. J Med Internet Res. 2008; 10(1): e5. PMID: 18343794 DOI: $10.2196 / j m i r .984$ [PubMed]

7. Centers for Disease Control and Prevention. Guidance for school administrators to help reduce the spread of seasonal influenza in K-12 schools. [Internet]. 2015 [updated 2016 Aug 05; cited 2016 Sep 11]. Available from: https://www.cdc.gov/flu/school/guidance.htm

8. Kickbusch I. Health literacy: An essential skill for the twentyfirst century. Journal of Health Education. 2008; 108(2): 1014.

9. Centers for Disease Control and Prevention. Key facts about seasonal flu vaccine. [Internet]. 2015 [updated 2016 Aug 05; cited 2016 Sep 11]. Available from: https://www.cdc.gov/flu/protect/keyfacts.htm

10. Asefzadeh S. Principles of health economics. Hadis-e-Emruz Publication; Tehran, Iran. 2008.

11. Sharma A, Jain R. Dictionary of information technology. CBS Publishers \& Distributors; New Delhi, India. 2003.

12. Shoaeshargh F, Dadashi MA. Studying the effect of office automation on improving the decision making of Tajrish
Shohada hospital managers. Tech J Engin \& App Sci. 2013; 3(18): 2163-7.

13. Stoner AF, Freeman ER, Daniel R, Gilbert JR. Management: Introduction to management in the twenty-first Century, Planing. Parsaeyan A, Aarabi SM (trans). 2nd ed. Cultural Research Office; Tehran, Iran. 2003.

14. Yazdani BO, Yaghoubi NM, Giri ES. Factors affecting the empowerment of employees. European Journal of Social Sciences. 2011; 20 (2): 267-74.

15. Beheshtian $M$, Abolhassani H. Management information systems. Pardis Corp.; Tehran, Iran. 1999.

16. Boostanian $\mathrm{M}$. The effect of automation on inter-relationship of organization. Khoozestan Province Port and Sailing Administration. 2011.

17. Small $\mathrm{MH}$, Yasin M. Advanced manufacturing technology adoption and performance: the role of management information systems departments. Integrated Manufacturing Systems. 2003; 14(5): 409-22.

18. Sullivan F, Mitchell E. Has general practitioner computing made a difference to patient care. A systematic review of published reports. BMJ. 1995; 311(7009):848-52. PMID: 7580494 DOI: $10.1136 / \mathrm{bmj} .311 .7009 .848$ [PubMed]

19. Shea S, DuMouchel W, Bahamonde L. A meta-analysis of 16 randomized controlled trials to evaluate computer-based clinical reminder systems for preventive care in the ambulatory setting. J Am Med Inform Assoc. 1996; 3(6): 399409. PMID: 8930856 [PubMed]

20. McDonald CJ, Hui SL, Smith DM, Tierney WM, Cohen SJ, Weinberger $M$, et al. Reminders to physicians from an introspective computer medical record: A two-year randomized trial. Ann Intern Med. 1984; 100(1): 130-8. PMID: 6691639 [PubMed]

21. McDonald CJ, Hui SL, Tierney WM. Effects of computer reminders for influenza vaccination on morbidity during influenza epidemics. MD Comput. 1992; 9(5) :304-12. PMID: 1522792 [PubMed]

22. McDonald CJ, Overhage JM, Tierney WM, Abernathy GR, Dexter PR. The promise of computerized feedback systems for diabetes care. Ann Intern Med. 1996; 124(1): 1704. PMID: 8554213 [PubMed]

23. Overhage JM, Tierney WM, McDonald CJ. Computer reminders to implement preventive care guidelines for hospitalized patients. Arch Intern Med. 1996; 156(14): 1551-6. PMID: 8687263 [PubMed]

24. Ansari M. The effect of applying office automation system on employee's productivity. [Internet]. 2013. [cited 2016 Sep 11]. Available from: www.system.parsiblog.com

25. Tierney WM, Overhage JM, Takesue BY, Harris LE, Murray MD, Vargo DL, et al. Computerizing guidelines to improve care and patient outcomes: the example of heart failure. J Am Med Inform Assoc. 1995; 2(5): 316-22. PMID: 7496881 [PubMed]

26. Briss $P$, Ndiaye SM, Rodewald L. Vaccine preventable diseases. In: Zaza S, Briss PA, Harris KW (eds). The guide to community preventive services: What works to promote health? Oxford University Press. 2009.

27. Briss PA, Rodewald LE, Hinman AR, Shefer AM, Strikas RA, Bernier RR, et al. Reviews of evidence regarding interventions to improve vaccination coverage in children, adolescents, and adults: The task force on community preventive services. Am J Prev Med. 2000; 18(1 Suppl): 97140. PMID: 10806982 [PubMed]

28. Centers for Disease Control and Prevention. The flu: Caring for someone sick at home. [Internet]. 2010. [updated 2010 
Dec 01; cited 2016 Sep 11]. Available from: https://www.cdc.gov/flu/pdf/freeresources/general/influ enza_flu_homecare_guide.pdf

29. $\mathrm{Yu}$ E. The role of telemedicine in disease prevention in Hong Kong. [Internet]. 2013. [updated 2013 Apr 26; cited 2015 Sep 11]. Available from: https://hongkongbusiness.hk/healthcare/commentary/rol e-telemedicine-in-disease-prevention-in-hong-kong

30. Blozik E, Grandchamp C, von Overbeck J. Influenza surveillance using data from a telemedicine center. Int J Public Health. 2012; 57(2): 447-52. PMID: 21318326 DOI: 10.1007/s00038-011-0240-1 [PubMed] 